\title{
UN IM ED: história e características da cooperativa de trabalho médico no Brasil
}

\author{
UNIMED: history and characteristics \\ of a Brazilian medical cooperative
}

Cristina Maria Rabelais Duarte $1,2,3$

\footnotetext{
1 Departamento de Ciências Sociais, Escola Nacional de Saúde Pública, Fundação Oswaldo Cruz. Rua Leopoldo Bulhões 1480, Rio de Janeiro, RJ 21041-210, Brasil. 2 Faculdade de Medicina de Petrópolis. Rua Machado Fagundes 326, Petrópolis,RJ 25716-970, Brasil.

3 Faculdade Arthur Sá Earp Neto. Rua Machado Fagundes 326, Petrópolis, RJ 25716-970, Brasil. rabelais@terra.com.br
}

Abstract This article describes the organizational characteristics of the UNIMED medical cooperative in Brazil. After an overview of UNIMED's share in the current health plan market, the author analyzes its organizational structure, historical evolution, and contractual regi men with member physicians, including the formula used to calculate the payment schedule for physician services. The plan currently includes 367 local member cooperati ves, operating in over $80 \%$ of Brazil's counties, with $41 \%$ of existing physi cians to serve $7 \%$ of the population. The organization's history began with local cooperatives and subsequently federations, the confederati on, and other companies in the group. The organizational design and dynamics favor a high degree of decentralization and autonomy, subordination of all components in the system to the physician cooperative command, and the occurrence of internal disputes and conflicts between individual interests and those of the organization.

Key words Heal th Services; Health Policy; Health Insurance

Resumo O presente trabalho busca descrever as características organizacionais da cooperativa de trabal ho médico UNIMED no Brasil. Após uma breve perspectiva sobre a partici pação da UNIM ED no mercado atual, aborda-se sua estrutura organizacional, evolução histórica e o regime contratual dos cooperados, incluindo a fórmula utilizada para o cál culo do valor a ser pago como remuneração do trabal ho médico. Atual mente, são 367 cooperativas l ocais no país, que operam em mais de $80 \%$ dos municípios, contando com $41 \%$ dos médi cos existentes para atender a 7\% da população. A história da organização evi dencia o surgimento, primeiro, das cooperativas locais e, posteriormente, daquel as das federações, da confederação e das demais empresas do complexo. O desenho e a dinâmica organizacional favorecem o al to grau de descentralização e autonomia; a subordi nação de todos os componentes do compl exo ao comando da cooperativa de trabal ho médico ea ocorrência de disputas internas e conflitos entre os interesses indivi duais e os da organização.

Palavras-chave Serviços de Saúde; Política de Saúde; Seguro Saúde 
Introdução

O presente trabalho tem como objetivo descrever o perfil da cooperativa de trabal ho médico UNIMED no País. Após uma breve perspectiva sobre a participação da UNIMED no mercado atual de saúde supletiva, aborda-se sua estrutura organizacional, evolução histórica e o regime contratual dos cooperados, incluindo a fórmula utilizada para o cálculo do val or a ser pago como remuneração do trabalho médico. Indicadores de cobertura populacional e grau de adesão de médicos no território nacional são apresentados no decorrer do trabalho.

\section{Metodologia}

A estrutura da organização foi desenhada com base na tipologia proposta por Mintzberg (1989), procurando-se destacar as principais características e problemas associados às organizações cuja força de trabalho se constitui predominantemente por especial istas altamente treinados, os profissionais.

As informações sobre o complexo UNI MED foram obtidas em fontes documentais e entrevistas. No primeiro caso, foram utilizados documentos oficiais fornecidos pela Confederação UNIMED - Estatuto da Confederação UNIMED do Brasil, Constituição UNIMED, relatórios específicos, documentos de circulação interna e de divulgação - e informações disponíveis na internet, no site da Confederação UNIMED do Brasil (http:// www.unimed.com.br).

As entrevistas, semi-estruturadas, foram real izadas em 20 de jun ho e 20 de outubro de 1998, respectivamente, com o diretor financeiro, Dr. Humberto Banal Batista da Silva, e com o presidente da Confederação UNIMED do Brasil, Dr. Edmundo Castilho, considerados informantes privilegiados, em virtude das funções que desempenham atualmente e do largo período de tempo em que são dirigentes do complexo. $O$ atual presidente da Confederação UNIM ED foi também fundador da primeira cooperativa local do País, e o diretor financeiro foi diretor executivo da UNIMED-Petrópolis no período de 1989 a 1997.

Vale mencionar que o acesso privilegiado a informações e documentos, inclusive de circulação interna, foi facilitado pela existência de uma relação prévia, de acompanhamento do trabal ho da diretoria da UNIMED-Petrópolis, durante o período de 1992 a 1994.

As informações foram coletadas no segundo semestre de 1998 e início de 1999, período em que a UN IM ED se adaptava às exigências da Lei 9.656, de 3 de junho de 1998 (Brasil, 1998).
A UNIMED no âmbito da assistência médica supletiva

Atualmente, a assistência médica supletiva está integrada por quatro modalidades assistenciais principais: a medicina de grupo, as cooperativas médicas, os planos próprios das empresase o seguro-saúde. Cada uma, cujas características são encontradas de forma detalhada em Bahia (1999), Guerra (1998) ou Mendes (1993), apresenta racionalidades de estruturação, clientelas e formas de financiamento diversas. Para o escopo deste trabal ho, segue uma defini ção esquemática, que considera as formas de constituição das empresas, as diferenças na gestão do risco e a disponibilidade de infra-estrutura para atendimento ao usuário. A gestão do risco pode assumir duas condições: na primeira, a empresa prestadora assume o risco em troca de um pré-pagamento mensal por parte do contratante (empresa ou pessoa física) e, na segun$\mathrm{da}$, o contratante assume os riscos, pagando somente pelos serviços efetivamente utilizados (regime de pós-pagamento). $\mathrm{O}$ atendimento ao usuário pode variar entre a livre escolha de médicos e serviços e a disponibilidade de rede própria, credenciada ou sistemas mistos.

Empresas de medicina de grupo são aquelas que se dedicam à prestação de assi stência médico-hospitalar mediante contraprestações pecuniárias - em regime de pré-pagamento -, com ou sem fins lucrativos. Subdividem-se naquelas que mantêm uma infra-estrutura baseada, essencialmente, em recursos próprios, sendo os médicos seus empregados, ou as que utilizam recursos credenciados. Algumas oferecem, para planos diferenciados, o sistema de livre escol ha com reembolso, destinados aos níveis hierárquicos superiores das empresas (Towers Perrin, 1997).

As seguradoras operam em conjunto com instituições fin anceiras e comercializam planos unicamente pelo sistema de reembolso, caracterizando-se pela livre escolha exclusiva ou pela oferta adicional de uma rede credenciada para o atendimento.

Nos modalidade de autogestão, as empresas elaboram o desenho de seus planos de saúde e definem as regras de operacional ização. Elas arcam com os riscos, utilizando o regime de pagamento por serviços prestados. Podem administrar o plano diretamente ou contratar uma administradora especializada e, para o atendimento, podem dispor de serviços próprios, geralmente ambulatórios, e/ ou utilizar a rede credenciada.

As cooperativas são formalmente definidas como sociedades que se constituem para pres- 
tar serviços a seus associados, com vistas ao interesse comum e sem o objetivo de lucro. Podem ser formadas por vinte participantes no mínimo, denominados cooperados, que, ao ingressar, integralizam um capital em quotas. As cooperativas que comercializam planos de saúde são compostas por médicos cooperados responsáveis pelo atendimento aos usuários em consultórios particulares próprios ou em hospitais, laboratórios e clínicas credenciados. Em geral, operam em regime de pré-pagamento, ou, eventualmente, de pagamento por custo operacional (despesas por atendimentos efetivamente realizados, acrescidas de taxa de administração). Não há alternativa para o sistema de livre escolha com reembolso. A Cooperativa deTrabalho Médico UNIM ED corresponde praticamente à totalidade deste segmento.

Dados citados por Bahia (1999) apontam que as empresas de medicina de grupo e as cooperativas detêm mais de $70 \%$ do mercado, sendo que as primeiras possuem em torno de 18 milhões de clientes, e a UNIMED, 11 milhões. Os planos de autogestão atendem a oito miIhões de clientes, e as seguradoras, a cinco miIhões. O segmento de medicina de grupo é composto por um conjunto de várias empresas e, em 1999, as maiores eram a Amil, com oitocentos mil clientes, a Intermédica e a Interclínicas, com seiscentos mil clientes cada. Num ranking que considere as empresas isoladas, as cooperativas da UNIMED ocupam o primeiro lugar em termos de mercado, detendo uma parte significativamente maior que a das demais concorrentes.

\section{A estrutura organizacional da UNIMED}

Sendo o complexo empresarial UNIMED uma organização voltada para a prestação de serviços de saúde e de assistência médica, o ponto de partida para a descrição de sua estrutura organizacional foi o desenho proposto por Mintzberg (1989) para as organizações profissionais (professional organization). Esta abordagem tem sido utilizada por outros autores (Azevedo, 1993; Dussault, 1992), que a consideram útil para compreender o funcionamento de organizações da área de saúde.

Neste tipo de configuração de Mintzberg, prevalece, como principal mecanismo de coordenação, a padronização de habilidades: os profissionais, altamente especializados, são treinados e doutrinados por instituições formadoras externas ao ambiente da organização - as instituições de ensino - e sua conduta é regulada pelos de órgãos de classe. Além da ele- vada especialização, destaca-se também a descentralização horizontal, entendida como a extensão em que o poder formal ou informal é dispersado da linha hierárquica para as partes não gerenciais da estrutura. Assi m, a parte chave da estrutura éo núcleo operacional (responsável direto pela produção de bens ou prestação de serviços), que atua com al to grau de autonomia sobre seu trabalho.

Além de caracterizar uma organização profissional na concepção de Mintzberg, a UNIMED é uma empresa cooperativa, com modelo organizacional específico e diferenciado em relação às empresas tradicionais. Os principais traços que distinguem uma cooperativa são a participação dos cooperados nos processos decisórios - cada trabalhador, um voto - e a divisão do lucro conforme o trabal ho e não conforme o capital (Pinho, 1982, 1987; Schneider, 1998).

A combinação de características desses dois modelos de organização imprime à UNIMED uma história e um desenho peculiares, os quais expressam os caminhos percorridos por dirigentes da categoria médica para conformar uma organização capaz de otimizar as possibilidades de ocupação do mercado de trabalho e fugir da submissão salarial a empresas médicas, adotando o discurso do exercício liberal, ético e socialmente comprometido da profissão.

\section{As origens da UN IMED}

A fundação da primeira cooperativa UNIMED partiu da mobilização de dirigentes do sindicato da classe, em Santos, São Paulo, como uma reação ao surgimento das primeiras empresas de medicina de grupo criadas por advogados, empresários ou grupos de médicos não vinculados ao movimento da categoria. Segundo o atual presidente da Confederação Nacional das UNIMEDs, presidente do Sindicato dos Médicos de Santos na época e também fundador da primeira singular: “Em 1967, em Santos, nós criamos a primeira UNIMED, baseados no fato deque nós não queríamos a mercantilização, nós queríamos a ética, o respei to aos usuários. E definimos o atendimento em consultório, (...), socializando mei os e mantendo as característi cas li berais" (Edmundo Castilho, comunicação pessoal).

No discurso, o exercício da medicina chamada liberal estava associado a uma qualidade melhor da assistência prestada: “Osmédicosassociados, sendo os proprietários, receberiam a justa remuneração por seu trabalho em troca de um al to padrão deatendimento aos usuários" (Akamine, 1997:37). 
A partir dessa primeira experiência, várias UNIMEDs foram criadas e, em 1977, eram 60 em todo o Brasil. No início da década de 70, surgiram as primeiras federações: São Paulo, Minas Gerais e Rio Grande do Sul. A confederação foi fundada, em 1972, em meio a mais uma disputa: informados sobre a intenção da Associação Médica Brasileira (AMB) de fundar uma confederação e assumir o seu comando, alguns dirigentes de federações anteciparam-se e criaram a confederação por meio de um protocolo de intenções (Humberto Banal Batista da Silva, comunicação pessoal).

Com o passar do tempo, foram sendo constituídas outras estruturas, destinadas a prestar serviços complementares à atividade-fim da cooperativa médica. Atualmente, a organização UNIMED é composta por um complexo que reúne diferentes entidades jurídicas interligadas. O Complexo Multicooperativo e Empresarial UNIMED é definido como "a reunião, numa instituição de caráter virtual, de trêstipos diferentes de cooperati vas,(...),juntamente com instituições não-cooperativas, tanto com espírito não lucrativo, como outras com obj etivos delucro" (I rion, 1998:99). Reúne sistemas ou segmentos de diferentes atividades e naturezas jurídicas. São eles:

- O sistema multicooperativo, que congrega o sistema UNIMED - cooperativas de trabalho médico; o sistema UNICRED - cooperativas de economia e crédito mútuo; e as cooperativas USIMED - cooperativas de consumo.

- O sistema empresarial, que abrange instituições não cooperativistas, representadas por empresas de capital com o objetivo de lucro e uma fundação sem fins lucrativos. São elas: a Seguradora; a Corretora de Seguros; a UNIMED Participações; a UNIMED Administração e Serviços; a Fundação Centro de Estudos UNIMED e, segundo Akamine (1997), a UNI MED Sistemas; a U NIMED Produtos e Serviços Hospitalares e a UNIMED Tecnologia, Comércio, Indústria e Serviços Ltda (UNINTEL).

\section{Os componentes do complexo}

O Complexo Multicooperativo Empresarial UNIMED tem abrangência nacional eé descrito em seus conceitos, princípios e operações na Constituição UNIMED, revisada em outubro de 1994 (UNIMED, 1997a). A cooperativa de trabaIho médico é a estrutura que agrega as demais, tendo como lógica organizadora a área geográfica ou mercado de atuação.

Como cooperativa, a UNIMED negocia, em nome dos profissionais, contratos de prestação de serviços, tendo como clientes pessoas jurídicas ou físicas. Apresenta, como missão, “o obje tivo deagregar profissionais médicos para defesa do exercício liberal, éti co e qual itativo de sua profi ssão, com adequadas condi ções de trabaIho e remuneração justa, além de propiciar, à mai or parcela possível da população, um serviço médi co de boa qualidade, personal izado e a custo compatível" (UNIMED, 1994).

Sua estrutura está organizada em cooperativas de diferentes graus, a saber: cooperativas de primeiro grau ou basilares, denominadas singulares, com áreas de atuação exclusivas (um ou mais municípios); cooperativas de segundo grau ou federações que, dependendo de sua área de ação, podem ser intrafederativas estaduais ou regionais - ou interfederativas e a cooperativa de terceiro grau, constituída pela confederação de âmbito nacional, UNIMED do Brasil (UNIMED, 1996).

O médicos filiam-se às cooperativas de primeiro grau, as quais se vinculam às federações; estas, por sua vez, estão ligadas à confederação. A função expressa das cooperativas em todos os graus é prestar servi ços aos seus associados. Não existe, formal ou informalmente, sistema decisório hierárquico estabelecido entre os diferentes graus, sendo as singulares autônomas e independentes, nos aspectos jurídico, econômico e administrativo.

Duas singulares não podem apresentar coincidência na área de ação, e apenas às federações é permitido coincidência parcial. As UNIMEDs de segundo e terceiro graus podem negociar contratos respectivamente com empresas de âmbito de atuação regional ou nacional, enquanto as singulares limitam-se à esfera local. Os atendimentos são realizados na rede de UNIMEDs locais, a partir do repasse de pagamento, mecanismo que possibilita o intercâmbio de aten dimento entre as singulares, o que amplia fortemente a rede de serviços em nível nacional.

Em 1997, a Federação Norte/ Nordeste decretou-se um grupo dissidente do complexo, fundando a Aliança UNIMED. Desde então, tem havido uma disputa interna pela adesão das singulares e federações, bem como pelo direito de uso da marca UNIMED. Em termos formais, até o momento, o sistema permanece unificado, congregando 364 cooperativas, noventa mil médicos cooperados e 11 milhões de usuários (UNIMED, 2000). Em 1996, a UNIMED estava presente em 3.951 municípios (Confederação Nacional das Cooperativas Médicas, 1996, 1998), aproximadamente $80 \%$ dos existentes no país na ocasião (IBGE, 2000).

A Tabela 1 traz o número de usuários e cooperados, de acordo com as singulares e federa- 
Número de singulares, usuários e médicos cooperados existentes em 1998 e estimativa de cobertura populacional e grau de adesão dos médicos, segundo estados das federações UNIMED.

\begin{tabular}{|c|c|c|c|c|c|c|c|}
\hline \multirow{2}{*}{$\begin{array}{l}\text { Federações UNIMED, } \\
\text { segundo estados } \\
\text { de abrangência }\end{array}$} & \multicolumn{5}{|c|}{ Sistema cooperativo UNIMED } & \multirow{2}{*}{$\begin{array}{l}\text { Cooperados por } \\
1.000 \text { usuários }\end{array}$} & \multirow{2}{*}{$\begin{array}{l}\text { Médicos por } \\
1.000 \text { habitantes }\end{array}$} \\
\hline & Singulares $(n)^{1}$ & Usuários (n)1 & Cooperados $(n)^{1}$ & $\begin{array}{l}\text { Médicos } \\
\text { cooperados } \\
\text { no local }(n)^{2}\end{array}$ & $\begin{array}{l}\text { População } \\
\text { coberta }(n)^{3}\end{array}$ & & \\
\hline Norte & 11 & 299.330 & 2.528 & 43 & 3 & 8,45 & 0,57 \\
\hline $\begin{array}{l}\text { Amazônia ocidental } \\
\text { (A mazonas, Acre, } \\
\text { Rondônia e Roraima) }\end{array}$ & 7 & 188.438 & 1.248 & 57 & 4 & 6,62 & 0,51 \\
\hline $\begin{array}{l}\text { A mazônia oriental } \\
\text { (Amapá e Pará) }\end{array}$ & 4 & 110.892 & 1.280 & 35 & 2 & 11,54 & 0,62 \\
\hline Nordeste & 63 & 1.005 .643 & 15.957 & 48 & 2 & 15,87 & 0,74 \\
\hline Alagoas/Sergipe & 6 & 131.678 & 1.915 & 49 & 3 & 14,54 & 0,92 \\
\hline Bahia & 17 & 201.037 & 2.690 & 31 & 2 & 13,38 & 0,70 \\
\hline Ceará & 12 & 246.002 & 3.879 & 85 & 4 & 15,77 & 0,67 \\
\hline Paraíba & 5 & 126.044 & 1.685 & 56 & 4 & 13,37 & 0,91 \\
\hline Pernambuco & 9 & 116.713 & 2.667 & 36 & 2 & 22,85 & 1,00 \\
\hline Piauí & 4 & 24.185 & 652 & 46 & 1 & 26,96 & 0,53 \\
\hline Rio Grande do Norte & 7 & 127.198 & 1.940 & 86 & 5 & 15,25 & 0,88 \\
\hline Maranhão & 3 & 32.786 & 529 & 28 & 1 & 16,13 & 0,36 \\
\hline Centro-oeste & 31 & 593.011 & 6.329 & 49 & 5 & 10,67 & 1,12 \\
\hline Goiás/Tocantins & 20 & 306.136 & 3.536 & 37 & 4 & 11,55 & 1,30 \\
\hline Mato Grosso & 6 & 146.193 & 1.069 & 71 & 7 & 7,31 & 0,67 \\
\hline Mato Grosso do Sul & 5 & 140.682 & 1.724 & 95 & 7 & 12,25 & 0,94 \\
\hline Sudeste & 159 & 6.225 .842 & 36.253 & 31 & 9 & 5,82 & 1,75 \\
\hline Minas Gerais & 64 & 1.730 .962 & 6.107 & 32 & 10 & 3,53 & 1,15 \\
\hline Rio de J aneiro & 21 & 654.270 & 9.132 & 25 & 5 & 13,96 & 2,75 \\
\hline Espírito Santo & 5 & 234.705 & 2.107 & 65 & 8 & 8,98 & 1,16 \\
\hline São Paulo & 69 & 3.605 .905 & 18.907 & 33 & 11 & 5,24 & 1,70 \\
\hline Sul & 69 & 2.389 .397 & 20.481 & 73 & 10 & 8,57 & 1,20 \\
\hline Paraná & 24 & 758.718 & 6.771 & 76 & 8 & 8,92 & 0,99 \\
\hline Rio Grande do Sul & 30 & 1.125 .265 & 10.483 & 71 & 12 & 9,32 & 1,54 \\
\hline Santa Catarina & 15 & 505.414 & 3.227 & 72 & 10 & 6,38 & 0,92 \\
\hline Brasil & 333 & 10.513 .223 & 81.548 & 41 & 7 & 7,76 & 1,26 \\
\hline
\end{tabular}

Fontes: 1 Confederação Nacional das Cooperativas Médicas (1998);

2 Denominador: Machado, 1997;

3 Denominador: IBGE, contagem de população de 1996

OBS: Os dados sobre a UNIMED abrangem 90,7\% das singulares (333 do universo de 367 existentes na época).

ções a que pertenciam em 1998. Nota-se que o sistema tem a adesão de $41 \%$ dos médicos e cobre cerca de $7 \%$ da população total, todavia, quando se observa a distribuição por regiões, esse padrão sofre variações. Na Região Sul, o grau de adesão dos médicos passa de $70 \%$, sendo o maior entre todos os estados. A cobertura populacional também é mais expressiva, superando a média nacional no Rio Grande do Sul e em Santa Catarina. A Região Sudeste apresenta os menores percentuais de adesão, com exceção do Espírito Santo, porém a cobertura populacional ultrapassa os $10 \%$ em M inas Gerais e em São Paulo. As demais regiões apresentam padrões semelhantes entre si, com destaque para o grau de adesão dos médicos no Ceará, Rio Grande do Norte, Mato Grosso e Mato Grosso do Sul.

A disponibilidade de médicos para o atendimento aos usuários aponta para expressivas 
desigualdades se comparada com aquela referente à população total (Tabela 1). O Estado do Piauí apresenta a maior oferta de médicos para os usuários do País, em contraste com a segunda menor disponibilidade para a população em geral, sem considerar a exceção da Região Amazônica. Em Pernambuco, o quantitativo de médicos disponíveis é cinqüenta vezes maior para usuários do que para a população em geral.

Os demais componentes do complexo UNIMED surgiram como decorrência da demanda da cooperativa médica. Em 1989 foi criada a primeira UNICRED, em Vale das Antas, Rio Grande do Sul, com o propósito de manter na corporação os recursos financeiros gerados pelo trabalho médico. Segundo o diretor financeiro da UNIMED Brasil, "assim, nosso dinheiro, não vai para o banco dos outros esim para o nosso banco" (Humberto Banal Batista da Silva, comunicação pessoal). O sistema UNICRED é constituído de: cooperativas de primeiro grau, destinadas à prestação de serviços às singulares médicas, seus cooperados e demais funcionários; cooperativas de segundo grau ou centrais e cooperativa de terceiro grau, constituída pela central nacional, com área de ação em todo o território brasileiro. Em 1997, congregava 86 cooperativas e 26 mil cooperados (UNIMED, 1997b). Embora seja um contingente expressivo, representa, apenas, 30\% dos médicos cooperados, o que evidencia um grau de adesão ainda bastante modesto.

A Cooperativa de Consumo USIMED foi instituída com o objetivo de promover o acesso dos usuários a preços mais vantajosos de medicamentos, materiais e equipamentos, remoção programada de pacientes e assistência prestada por profissionais não-médicos. Tratase de um sistema ainda em fase de implantação, iniciado em 1993, que funciona através de uma rede de farmácias, gerenciadas por vinte cooperativas que atendem a sessenta mil usuários (UNIMED, 1997b). O argumento apresentado foi o compromisso social do profissional médico de viabilizar o tratamento para o usuário da UNIMED, ensejando a aquisição de medicamentos a preços menores que os praticados pelo restante do mercado. Tendo em vista que o Código de Ética Médica (CFM, 1988:7), em seu artigo 98, proíbe o exercício da profissão “com interação ou dependência de farmácia", os médicos foram transformados juridicamente em consumidores e, em conjunto com os usuários da UNIMED, tornaram-se cooperados da USIMED.

O sistema empresarial foi criado para possibilitar o desenvolvimento de atividades que, por força da legislação, não poderiam ser de- senvolvidas por cooperativas. Assim, para garantir o controle sobre essas empresas e a prestação de serviços exclusivamente ao complexo, foram formulados seis princípios orientadores. São eles: (1) o sistema UNIMED deve ter a maioria do capital votante para assegurar o controle das empresas; (2) no caso de instituição organizada sob a forma de sociedade anônima, é admissível a participação acionária de médicos cooperados ou de outras instituições fora do complexo, desde que subscrevam ações preferenciais (sem direito a voto); (3) toda empresa criada deve estar a serviço do complexo, constituindo-se em instituição-meio e não em instituição-fim por si mesma; (4) a direção de cada empresa será exercida pelo diretor da UNIMED do Brasil, à qual se vincula a atividade principal da instituição; (5) nenhum diretor da UNIMED do Brasil pode acumular com sua função na diretoria da confederação mais de um cargo remunerado no sistema empresarial; (6) o processo decisório nas empresas, sempre que a legislação permitir, obedecerá ao princípio cooperativista da singularidade do voto (Irion, 1998).

A Seguradora surgiu em 1989 e sua atuação se dá no ramo dos seguros de vida, de previdência e de seguro-saúde, com clientelas específicas para cada produto. Os seguros-saúde estão disponíveis apenas para médicos cooperados e para dirigentes das empresas contratantes do sistema UNIMED. A única modalidade de seguro disponível para usuários é o seguro de vida em grupo. A Corretora de Seguros tem como objetivo colocar no mercado os produtos da Seguradora, sendo 99\% do capital da Corretora de propriedade da UNIMED do Brasil e $1 \%$ de um corretor habilitado.

Para evitar que a Cooperativa fosse a controladora da Seguradora, situação proibida por lei, criou-se uma empresa holding, a UNIMED Participações Ltda. É uma sociedade por quotas, sendo seus quotistas as cooperativas médicas e de crédito. Controla a UNIMED Seguradora e a UNIMED Administração e Serviços, preenchendo os correspondentes cargos diretivos. Segue os princípios cooperativistas da livre adesão (aberta ao ingresso de cooperativas) e da singularidade do voto (cada cooperativa tem direito a um voto, independente do capital aplicado). Sendo uma empresa de capital, seu lucro é distribuído entre as quotistas, na proporção do investimento aplicado.

A UNIMED Administração e Serviços foi criada para racional izar processos e produzir economia de escala, eliminando as estruturas de mesma natureza existentes nas diversas unidades do complexo. Unifica os sistemas de 
apoio da Confederação UNIM ED, da Seguradora, da Corretora e da UNIMED Participações, tendo pouca expressão nas singulares.

A Fundação Centro de Estudos UNIMED (CEU ) é a expressão de um dos princípios cooperativistas: o do doutrinamento (Pinho, 1982). $\mathrm{N}$ ão tem fins lucrativos e sua finali dade é divulgar o cooperativismo em geral e aquele praticado no complexo UNIMED. Visa, também, “...servir como ponto de apoio para os Comitês Educativos das Cooperativas, (...), centralizar acervos e talentos, realizar pesquisas, formar educadores e treinar dirigentes efuncionários do Complexo" (Irion, 1998:113).

Até o final da década de 80, a UNIMED não possuía hospitais próprios. As crescentes dificuldades nas negociações com os prestadores deram origem à fundação do primeiro hospital, em Brasília. Atualmente, embora ainda mantenha os estabelecimentos credenciados, a rede própria encontra-se em fase de expansão, integralizando 48 hospitais(UNIMED, 2000). A UNIMED Produtos e Serviços Hospitalares foi criada para possibilitar economia de escala e dar subsídios e sustentação tecnológicos para seu conjunto hospitalar. Apesar de sugerir a existência de uma rede integrada e administrada por uma empresa do complexo, a criação de novos hospitais e o seu gerenciamento são iniciativa e responsabilidade locais. A empresa congrega poucos hospitais e sua atuação está restrita à área de compras.

O complexo UNIMED possui também empresas voltadas ao desenvolvimento de tecnologias de informação. A UNIMED Tecnologia, Comércio, Indústria e Serviços Ltda, Unintel, foi criada recentemente com o objetivo de produzir os sistemas de transmissão de dados a serem utilizados por federações e singulares. Já a UNIMED Sistemas tem como objetivo a pesquisa e o desenvolvimento de produtos e serviços relacionados à organização e tecnologia da informação. Apesar de descrita como parte do sistema empresarial por Akamine (1997), atualmente, não possui o status de empresa isolada, constituindo-se no departamento de telemática da UNIMED do Brasil.

\section{O regime de contratação dos médicos}

Como apresentado, a cooperativa é uma modalidade de organização na qual os médicos são, simultaneamente, sócios e prestadores de serviços. Em alguns casos, podem ser funcionários das cooperativas, percebendo salários, como auditores ou plantonistas de hospitais próprios, mas, em sua maioria, são coopera- dos, recebendo pagamento proporcional à sua produção (por quantidade e tipo de procedimento).

A produção médica do cooperado é calculada em termos de unidade de trabalho (UT), sendo o ganho do profissional correspondente à multiplicação do número de UT realizado pelo valor estipulado para as mesmas. A quantidade de UT contida em cada procedimento médico corresponde à quantidade de coeficientes de honorários $(\mathrm{CH})$ publicada na tabela da AMB, sem consi derar seu valor monetário. Cada cooperativa real iza o cál culo do valor de sua UT, utilizando uma fórmula que divide a receita líquida pela produtividade total em número de $\mathrm{CH}$.

Quanto maior a receita líquida, denominada sobra, maior o valor recebido pelo profissional. Tal mecanismo de cálculo tem forte correspondência com o grau de utilização dos serviços pelos usuários, considerando-se que a maior parte da receita decorre da comercialização de planos do tipo pré-pagamento. Assim, num contexto de pouca utilização de serviços, os médicos trabalhariam menos, recebendo um valor mai or por cada ato ou procedimento. Entretanto, na percepção imediata do médico, a remuneração é fruto direto de sua produtividade, fato que, na prática, pode levá-lo a estimular uma maior utilização de serviços por parte dos usuários. Quando presente, essa distorção aumenta as despesas e diminui a receita líquida. Vale registrar que o gasto anual para custear a assistência médica na Confederação UNIMED correspondeu a cerca de $54 \%$ das despesas totais em 1997, tendo apresentado um aumento de $30 \%$ no gasto anual per capita em relação a 1996. Tais esti mativas foram realizadas com base em UNIMED (1998).

O valor da UT - e, em última anál ise, a remuneração do médico - pode variar no tempo e apresentar diferenças entre as di versas cooperativas. Segundo pesquisa realizada pela ge rência da UNIMED-Petrópolis, em 1998, o menor valor pago foi $\mathrm{R} \$ 0,18$, e o maior, $\mathrm{R} \$ 0,33$, sendo a média equivalente a $\mathrm{R} \$ 0,26$. No mesmo ano, a maioria das singulares estipulou em $\mathrm{R} \$ 0,25$ o val or da UT. Verificada na tabela da AMB de 1992 a correspondência de uma consulta médica a $100 \mathrm{CH}$, a maioria das singulares pagou $\mathrm{R} \$ 25,00$ a consulta, sem incluir outros procedimentos real izados durante o atendimento. 
O modelo UNIMED: organização

profissional e cooperativa de trabalho

Dentre os elementos que caracterizam as organizações profissionais tipificadas por Mintzberg, os mais importantes são, sem dúvida, os que abordam o papel desempenhado pelo núcleo operacional. Além de paradigmático, é responsável pelos problemas que, em geral, estão associados à dinâmica de organizações deste tipo.

O núcleo operacional da UNIMED é constituído por médicos, sendo sua atuação marcada por um alto grau de especialização, típico de profissionais treinados no domínio de conhecimentos e de habilidades indispensáveis ao desempenho de ações complexas. O desenvolvimento de tais atividades demandam um amplo espectro de autonomia e de controle sobre o processo de trabal ho, o que ocasiona umaescassa possibilidade de regul amentação das decisões técnicas.

O fato de ser uma organização do tipo cooperativa - de estrutura, por definição, descentral izada - intensifica certas características da organização profissional. No sistema UNIMED, as singulares dispõem de expressiva autonomia, e os profissionais que nel as atuam detêm um grande controle sobre seu processo de trabalho. Assim, a concentração do poder nas mãos do médico é potencializada, acrescendose à autoridade própria da natureza profissional, aquela decorrente da qual idade de cooperado.

Nesse contexto, torna-se difícil a implementação de modelos de planejamento ou controle de desempenho que abranjam todo o sistema. Mesmo em relação a procedimentos de controle de custo e inflação médica, observa-se grande variabilidade entre as singulares, tanto nos mecanismos implementados, como nos resultados obtidos, sem que se realize qualquer tipo de monitoramento sistemático destas experiências.

Embora, como tipificado por Mintzberg (1989), o tamanho das unidades para as organizações profissionais seja gran de no núcleo operacional e pequeno nos demais componentes, na UNIM ED, diferentemente, as instâncias principais da cúpula estratégica são formadas por um número expressivo de cooperados. $\mathrm{O}$ sistema decisório estrutura-se com base na Assembléia Geral - instância decisória máxima e nos colegiados eleitos: Consel ho Fiscal - colegiado curador fiscal -, Conselho Administrativo e Diretoria Executiva, sendo estes últimos órgãos executores. Nesse aspecto, também, a estrutura cooperativa potencializa os elemen- tos definidores da organização profissional: deliberações das diretorias executi vas - tanto do complexo como das singulares - necessitam ser legitimadas, sendo, muitas vezes, negociadas nos conselhos e assembléias ou mesmo em grupos de especialistas. Os médicos, além de controlar seu próprio trabalho, utilizam-se do sistema decisório existente para controlar as decisões que os afetam, interferindo de forma significativa nos rumos tomados pela organização.

No universo de configurações de Minstzberg (1989), as organ izações profissionais apresentam duas fontes principais de problemas, ambas se aplicando claramente à estrutura da UNIMED: as dificuldades de coordenação, já que, virtualmente, há pouco controle do trabaIho além daquele próprio da profissão, e a dificuldade no lidar com profissionais incompetentes ou inescrupulosos, que podem ocultar seus erros ou atuar de forma a privilegiar os próprios interesses, em detrimento daqueles dos clientes e da organização.

\section{Considerações finais}

A descrição do complexo cooperativo UNI MED e o histórico de sua constituição permitem uma noção da engenharia institucional que caracteriza a organização. A intenção de seus líderes e fundadores tem sido manter sob controle dos médicos um amplo conjunto de atividades relacionadas a uma prática definida por eles como liberal, desenvolvida no âmbito de uma organização complexa. Sua história revela uma traj etória marcada por negociações, disputas e pela intenção de mobilizar a categoria para, através de uma organização corporativa, garantir a autonomia na prática profissional e competir no mercado de trabal ho.

O modelo organizacional de bases cooperativistas, com instâncias decisórias colegiadas e divisão dos ganhos segundo a produção, revelou-se bastante atrativo para a categoria médica. Aliado à relativa facilidade com que uma singular é constituída, esse modelo pode explicar as expressivas taxas de adesão dos médicos e cobertura populacional alcançadas no País.

Uma eficiente estratégia de mercado utilizada é a denominada "unimilitância", isto é, a proibição de cooperados serem credenciados ou empregados de outros planos de saúde. $O$ argumento utilizado fundamenta-se na legislação cooperativista, que veda o ingresso de "agentes de comérci o e empresários que operem no mesmo campo econômico da sociedade" - § 40 do Artigo 29 da Lei no 5.764/ 71 - (Organização 
das Cooperativas Brasileiras/Ministério da Agricultura, 1987:15). Note-se que a restrição não se aplica à prestação eventual de serviços (Irion, 1997). É permitido ao médico atender o usuário de outro plano ou seguro, mediante pagamento direto (que poderá ser reembolsado ao usuário pelo seu plano original), porém é vedado ao profissional figurar nas listas de credenciados dos planos concorrentes. Em tese, o fato de os médicos serem sócios da cooperativa deveria constrangê-los a trabalhar para a concorrência, entretanto muitos consideram a unimilitância uma "camisa de força" impingi da pela UNIMED, e a adesão ao princípio não se constitui regra geral nas singulares. Outras estratégias utilizadas pela empresa incluem a diversificação de produtos e a definição de mercado por área geográfica.

Os traços mais importantes evidenciados na estrutura da UNIMED são a autonomia dos médicos em relação ao seu processo de trabaIho, típica de organizações profissionais, eo alto grau de descentralização, que caracteriza uma organização do tipo cooperativa. Tais características acentuam fortemente a principal dificuldade das organizações cuja força de trabalho é constituída por profissionais especializados: as funções de coordenação e de gerência. A autonomia das singulares faz com que a UNIMED pareça um conglomerado de pequenas empresas sem estrutura hierárquica. Todo o sistema gerencial e de planejamento é independente, podendo ser, ou não, desenvolvido de forma articulada com as federações e confederação - condição muitas vezes determinada pela afinidade política dos dirigentes. Até o momento, a organização não conta com um sistema de informações gerenciais implementado e, como conseqüência, não dispõe de dados sistemáticos e confiáveis sobre as atividades desenvolvidas pelas singulares. A UNICRED é uma exceção a esta regra, pois, por exigência do Banco Central, os balanços das cooperativas locais são sistematicamente enviados para as centrais e disponibilizados para publicação.

O desenho e a dinâmica organizacional favorecem, também, a conformação de uma arena de conflitos e disputas entre grupos, que vão desde aqueles restritos ao cotidiano das singulares até os de gran de proporção. A cisão ocorrida no complexo em 1998 é um claro exemplo desse ambiente, pois o grupo dissidente, perdedor nas últimas eleições para a confederação, não buscou criar uma nova estrutura, nem propôs mudanças significativas no sistema.

Como os cargos diretivos são temporários, eletivos e exercidos por médicos, o grau de profissional ização da gerência é pouco desenvolvido. É através da participação nos conseIhos e diretorias que os profissionais buscam o controle sobre as decisões administrativas que os afetam, e a tendência é defenderem seus interesses individuais ou de grupos específicos (os especialistas, por exemplo), mesmo quando contrários aos da organização. O sistema de pagamento por produtividade gera, também, condições favoráveis à manipulação no trato das necessidades dos clientes. Isto pode ocorrer, por exemplo, quando um profissional incrementa, desnecessariamente, o número de consultas ou de exames indicados para a solução de um determinado problema.

Uma dualidade permanente é identificada no interior do sistema cooperativo, marcado pela competição entre os objetivos da organização, quando explicitados - diminuir o grau de utilização dos serviços, para otimizar a relação receita/ despesa - , e os objetivos dos profissionais - aumentar seus ganhos, através do aumento da produtividade. Tal situação permeia, de maneira clara, os interesses e as demandas dos usuários.

Finalmente, vale lembrar que a UNIMED atravessa uma conjuntura de mudanças decorrentes da adaptação à nova lei. Alterações importantes vêm ocorrendo, como a recente estruturação de uma Operadora Central de Planos de Saúde, à qual as singulares se filiarão. Poderá ocorrer também uma redução na quantidade de pequenas cooperativas locais ou sua agregação a prestadoras de operadoras regionais. Como os órgãos fiscalizadores exigem o envio sistemático de um conjunto mínimo de informações, torna-se provável a implementação - não sem um alto grau de dificuldade - de um sistema de gerenciamento ou monitoramento vertical mais efetivo, aumentando o grau de coesão do sistema e diminuindo a autonomia administrativa das singulares.

Nesse cenário, as informações apresentadas no presente trabalho são passíveis de sofrer alterações em médio ou longo prazos, até que, não apenas a UNIMED, mas também as demais empresas que competem no mercado privado de oferta de serviços de saúde, demonstrem sua capacidade de adaptação às novas regras estabelecidas pela legislação em vigor. 


\section{Agradecimentos}

A Edmundo Castilho, presidente da Confederação UNIMED do Brasil, e a Humberto Banal Batista da Silva, diretor financeiro, pela disponibilidade e acesso às informações; a Miguel Abud Marcelino, pelas sugestões e críticas, e a Alcina Saldanha da Gama, pela cuidadosa revisão do texto. Trabalho apoiado pelo Conselho Nacional de Desenvolvimento Científico e Tecnológico (Proc. 142.972/97-5).

\section{Referências}

AKAMINE, O., 1997. UNIMED 30 Anos. São Paulo: Cartaz Editorial.

AZEVEDO, C. S., 1993. Gerência Hospitalar: A Visão dos Diretores de Hospitais Públi cos do Município do Rio de Janeiro. Dissertação de Mestrado, Rio de Janeiro: Universidade do Estado do Rio de Janeiro.

BAHIA, L., 1999. Mudanças e Padrões das Relações Público-Privado: Segurose Planos de Saúdeno Brasil. Tese de Doutorado, Rio de Janeiro: Escola Nacional de Saúde Pública, Fundação Oswaldo Cruz.

BRASIL, 1998. Lei 9.656, de3 de Junho de 1998. Dispõe sobre os Planos e Seguros Privados deAssistência à Saúde. 12 de Novembro de 2000 বttp:// www. planalto.gov.br/legisla.htm>.

CFM (Conselho Federal de Medicina), 1988. Código deÉtica M édica - Resolução CFM no 1.246/88,de 01/01/1988. Novembro de 1999 \ttp:// www.cfm. org.br>.

CONFEDERAÇÃO NACIONAL DAS COOPERATIVAS MÉDICAS, 1996. APO 145. 24 de Julho. São Paulo: Confederação Nacional das Cooperativas Médicas

CONFEDERAÇÃO NACION AL DAS COOPERATIVAS MÉDICAS, 1998. DDE 143, de 02 de Setembro. São Paulo: Confederação Nacional das Cooperativas Médicas.

DUSSAULT, G., 1992. A gestão dos serviços públicos de saúde: Características e exigências. Revista de Administração Pública, 26:2-19.

GUERRA, L. L., 1998. Estratégi a de Servi ços das Empresas que Operam Planos/Seguros de Saúde no Brasil: Cooperativas, Empresas de Medicina de Grupo e Seguradores. Rio de Janeiro: Fundação Escola Nacional de Seguros.

IBGE (Fundação Instituto Brasileiro de Geografia e Estatística), 2000. Resultados Definitivos da Contagem 96. 28 de julho de 2000. «ttp:// www.ibge. gov.br/ estatística/ população/conta.../default.snt>.

IRION, J. E., 1997. Dupla militância. In: Cooperativismo e Economia Social (J. E. Irion, org.), pp. 157160, São Paulo: Editora STS

IRION, J. E., 1998. O complexo UNIM ED. In: Compêndio de Cooperati vismo UNIMED (N. L. May, org.), pp. 99-114, Porto Alegre: WS Editor.
MENDES, E. V., 1993. As políticas de saúde no Brasil dos anos 80. In: Distrito Sanitário: O Processo Social de Mudança das Práticas Sanitárias do Sistema Único de Saúde (E. V. Mendes, org.), pp. 1992, São Paulo: Editora Hucitec/ Rio de Janeiro: ABRASCO

MINTZBERG, H., 1989. Mintzberg on Management. Insi de our StrangeWorld of Organizations. New York: The Free Press.

ORGANIZAÇÃO DAS COOPERATIVAS BRASILEIRAS/ MINISTÉRIO DA AGRICULTURA, 1987. Legislação Cooperativista e Resol uções do Consel ho Nacional de Cooperativismo. Brasília: Organização das Cooperativas Brasileiras/Ministério da Agricultura.

PINHO, D. B., 1982. Manual de Cooperativismo. v. 1, São Paulo: Conselho Nacional de Desenvolvimento Científico e Tecnológico.

PINHO, D. B., 1987. Evolución del Pensamiento Coope rativista. Cadernos de Cultura Cooperativa, 76. Buenos Aires: Intercoop Editora.

SCHNEIDER, J. O., 1998. As origens do cooperativismo moderno. In: Compêndio de Cooperativismo UNIMED (N. L. May, org.), pp. 21-34, Porto Alegre: WS Editor.

TOWERS PERRIN, 1997. Planos de Benefíci os no Brasil. XVIII Pesquisa. Rio de Janeiro: Towers Perrin.

UNIMED, 1994. Missão da UNIMED. São Paulo: UNIMED. (mimeo.)

UNIMED, 1996. Estatuto Social da UNIMED do Brasil. Reformado em 28 de Junho. São Paulo: UNIMED. (mimeo.)

UNIMED, 1997a. Constituição UNIMED. In: Cooperativismo e Economi a Social (J. E. Irion, org.), pp. 307-328, São Paulo: Editora STS.

UNIMED, 1997b. 27ạ Convenção Nacional UNIMED. Cobertura completa. Revista UNIMED, 53.

UNIMED, 1998. Administração dos Resultados. BaIanço Econômico-Financeiro de 1997. Anexo 1. São Paulo: UNIMED.

UNIMED, 2000. Nossa Rede. 12 de Julho de 2000 〈http://www.unimed.com.br/rede_2htm>. 